International Journal of Agriculture, Environment and Bioresearch

Vol. 5, No. 03; 2020

ISSN: $2456-8643$

\title{
ECONOMIC EFFICIENCY OF BIO-FORTIFIED VITAMIN-A CASSAVA PROCESSING IN SOUTH WESTERN, NIGERIA
}

\author{
Kolapoadetomiwa* And Fakokunde Akinbode. $O$. \\ Department Of Agricultural Economics, Faculty Of Agriculture,obafemi Awolowo University, Ile Ife, Osun State, \\ Nigeria \\ https://doi.org/10.35410/IJAEB.2020.5515
}

\begin{abstract}
The study specifically investigated the economic efficiency of bio-fortified cassava processors in South Western, Nigeria. Data were collected through a multistage sampling technique from 160 sampled bio-fortified cassava processors in the study area. Primary data were used for the study with the aid of a well-structured questionnaire. Descriptive statistics and stochastic frontier model were used to analyzed the data. The result of the study showed that the mean age of the processors was $48( \pm 11.36)$ and about $61 \%$ of the bio-fortified cassava processors were female. The result of the study showed that all the input variables were important in bio-fortified cassava processing. The implication of these finding is that if there is an increase in any of the variable input, the total cost of processing bio-fortified cassava will increase. The result of the study showed that the average economic efficiency of the bio-fortified cassava processors was 0.65 and that variables such as age, gender, experience, duration of processing and membership of association determines the technical efficiency of the bio-fortified cassava processors in SouthWestern, Nigeria. Efforts should be made by the government to restructure cooperatives societies in Nigeria so that bio-fortified cassava processors would be encourage to join and have access to information that will improve their economic efficiency
\end{abstract}

Keywords: Economic efficiency, Stochastic frontier, technical efficiency, Bio-fortified cassava, processors, South Western, Nigeria.

\section{INTRODUCTION}

Cassava is an important staple food in Nigeria. Cassava is a starchy crop which contributes to the staples of millions in sub-Saharan Africa (SSA). According to Parkes et al. (2013), about 121 million tonnes of cassava were produced in Africa. Nigeria is regarded as the world's largest producer of cassava with a total of about 77 percent of the world export in year 2005. Cassava is a major staple food crop in Nigeria. As defined by IITA (IITA, 2007), a staple crop is the one that is been eaten regularly and which also provides larger proportions of the population's nutrients. Cassava fulfil this purpose as it can be eaten raw or in a processed form. Cassava is an essential component of the diet of about 70 million Nigerians (FAO, 2003). Nigeria, being the largest producer of cassava in the world is producing an average annual estimate of 45 million metric tons which had been translated into a major global market share of about 19 percent (Hillocks, (2002);Phillipset al., 2004). 
Cassava as a staple crop is regarded as a versatile commodity with many uses and by-products. The roots of cassava can be processed for industrial and human consumption. Different products, such as garri, wet pulp, cassava flour, starch, dried cassava and smoked cassava ballsmay be derived from cassava (Truman et al., 2004). Most root crops were predominantly white in color and they do not contain bio-fortified vitamin-A. However, over the decades, series of intervention programs have come into existence targeted towards improving human diets due to increasing incomes and also administration of vitamin-A capsules (Ilona et al., 2017; Egesi et al., 2006). The production of biofortified vitamin-A cassava started in 2011 with the intervention of the International Center for Tropical Agriculture (CIAT) and the International Institute of Tropical Agriculture (IITA) which were funded by Harvest Plus program. Five years after the intervention program, statistics revealed that over 1million of Nigerian farming households grows yellow cassava varieties that contains substantial quantities of vitamin-A even after processing. In Nigeria diets today, yellow bio-fortified cassava represents additional source of vitamin A (Saltzman et al., 2014).

In Nigeria, vitamin-A cassava after processing is predominantly consumed as garri which means "free flowing creamy white or yellow granular partially gelatinized flour produced from cassava" (Cardoso et al., 2005). Garriis produced through the process of peeling, washing, grating, bagging and dehydration (with the aid of hydraulic press), fermentation, sieving, frying, cooling and packaging. Garrislongevity and also ease of preparation (as compared to other cassava food products) makes it a widely consumed food (Sanni et al., 2008). Preferences for garri varies across regions and ethnic groups in Nigeria. It has been shown that there are positive contributions of bio-fortified vitamin-A garri in human diet as it provides up to $40 \%$ of vitamin A required, rich in beta-carotene with a better source of energy as compared to local white garri; food like vitamin-A cassava moimoi fortified with beans and cassava custard is of good quality for children; pro-vitamin-A eba/garri (natural, without additional oil) has a good curling quality in lafun/eba (Talsma et al., 2016).

Thus, it can be said that Nigerians derive much of their food and employment from cassava production, processing and marketing of cassava based agro-industrial schemes. Lawal and Jaiyeola (2007) elucidate that value addition increases the shelf-life of many agricultural products and also generates income for the participants. Majority of the government intervention programs and policies were aimed at integrating the rural poor into the mainstream of the national economy, one of the best ways to achieve this is by adding value to their agricultural produce, which normally involves numerous actors at different value addition chain. These actors among others include input suppliers, extension, producers/ farmers, processors, transporters, marketers, end-users, etc. These identified actors play major roles in maintaining the cassava value chain. Furthermore, them ostprominentandindispensableactorin the value chain istheprocessors who ensures that the bio-fortified cassava root, that is highly perishable with a very short shelf-life is processed into intermediate or finished products. However, for the processor to stay in business and consistently fulfil their portion of value addition, efficient use of inputs/resources is important.

In Nigeria today, few studies (Chukwujiet al., (2006);Ehinmowo and Ojo (2014);Adeniyiet al., (2015) and Abass et al., 2019) were conducted so far on technical efficiency of cassava 
processing. It is pertinent to identified that all these studies were conducted on local white garri in different state of the federation. Currently, no research had been conducted on economic efficiency of bio-fortified vitamin-A processing in Nigeria. Thus, it is therefore important to carry out a study of this nature to analyzed the economic efficiency of the bio-fortified vitamin-A processors in South Western Nigeria. The evaluation of the present efficiency of small scale biofortified cassava processing in South Western, Nigeria is therefore imperative. The main objective of this study was to described the socio-economic characteristics of the bio-fortified cassava processors and to analyze the economic efficiency of bio-fortified cassava processing firms in South Western, Nigeria. This study enabled us to identify the main driving factors of bio-fortified cassava processing efficiency in South Western, Nigeria.

\section{METHODOLOGY}

\section{Area of Study}

The study was carried out in South-Western region of Nigeria. The South-West region of Nigeria represents a geographical area covering latitude $6^{0}$ North and $4^{0}$ South. The South-Western region of Nigeria comprises of six states including Osun, Ekiti, Oyo, Ondo, Lagos and Ogun State. The region is bounded in the north by Kogi and Kwara States, in the South by Atlantic Ocean, in the west by Republic of Benin and in the East by Edo and Delta State. The South western region of Nigeria can boost of different varieties of arable food crops since the climatic conditions support the production of various food crops including cassava, maize, groundnut etc. A large proportion of the bio-fortified cassava were being produced and processed in South Western region of Nigeria, as the region was a major target for the production of the bio-fortified cassava, hence the choice of the study area for the study.

\section{Sampling procedures and sample size}

Multistage sampling procedures were employed for the study. The first stage involved purposive selection of two States including Oyo and Osun States due to availability bio-fortifiedcassava processors in the State. The second stage involved the purposive selection of two Local Government Areas because of the concentration of bio-fortified cassava processors in the areas. The third stage involved random selection of two communities from each of the selected LGAs. At the fourth stage, twenty bio-fortifiedcassava processors were purposively selected from each community to make a total of 160 (One hundred and sixty) respondents. Primary data were used for the study. The primary data were sourced from cross-sectional survey of bio-fortifiedcassava processors in the study area with the aid of well-structured questionnaire to cover information about the socioeconomic characteristics of respondent and inputs resource use in processing. Data were collected during the period of June, 2019- Oct, 2019.

\section{Analytical techniques}

The data were analyzed using descriptive and Stochastic Frontier model

\section{Descriptive statistics}

Descriptive statistics were used to described the socio-economic characteristics of the biofortified cassava processors in the study area.

\section{Stochastic frontier models}


Stochastic frontier model was used to specify factors affecting the efficiency of bio-fortified cassava processing. The stochastic frontier production model for the study is expressed in equation1 as:

$$
Y i=\beta_{o}+\sum_{k=1}^{4} \beta_{k} X_{k i}+\frac{1}{2} \sum_{k=1}^{4} \sum_{j=1}^{4} \beta_{k} X_{k i} X_{j i}+V_{i}-U_{i}
$$

where,

$Y i s t a n d s$ for the observed individual $i$ th processor's output $(\mathrm{kg})$;

$\mathrm{X}_{1}$ represents the quantity of tubers of cassava root (per $\mathrm{kg}$ ) used by the $i$ th processor;

$\mathrm{X}_{2}$ indicates labor input consisting of family and hired labor (man-days perhour);

$\mathrm{X}_{3}$ shows the quantity of wood/charcoal/diesel/petrol used, and;

$\mathrm{X}_{4}$ represents depreciation on equipment on $i$ th processing site (in Naira);

$\beta_{o}=$ vector of unknown parameters estimated

$V i=$ are random variables associated with random factors; and

$U i=$ which are non-negative random variables which are assumed to account for technical inefficiency in production.

Accordingly, technical efficiency (TE) of an individual processor is defined in terms of the ratio of the observed $\left(\mathrm{Yi}^{*}\right)$ output to the corresponding frontier output $(\mathrm{Yi})$, conditioned on the level of inputs used by the processor. Technical inefficiency is therefore defined as the amount by which the level of production for the processor is less than the frontier output. This is shown in the equation below:

$$
T E_{i}=\frac{Y i^{*}}{Y i}=\frac{f(X i \beta) \exp (V i-U i)}{f(X i \beta) \exp (V i)}=\exp (-U i)
$$

The stochastic cost function which is the basis for estimating the allocative efficiency (AE) of the processors firm is specified as follows:

$C i=\alpha_{o}+\sum_{k=1}^{4} \alpha_{k} P_{k i}+\frac{1}{2} \sum_{k=1}^{n} \sum_{i=0}^{n} \alpha_{k j} P_{k i} P_{j i}+V_{i}-U_{i}$

where,

$C_{i}$ stands for the total cost of processing the bio-fortified cassava output of $i$ th firm on per $\mathrm{kg}$ basis ( $)$;

$\mathrm{P}_{1}$ indicates cost of tubers of cassava rootper $\mathrm{kg}(\mathrm{N})$;

$\mathrm{P}_{2}$ indicates cost of total quantity of family (opportunity cost) and hired labour man-days required to perform various processing activities on the $i$ th site ( $)$;

$\mathrm{P}_{3}$ shows cost of quantity of wood/charcoal/diesel/petrol used on $i$ th site ( $)$;

$\mathrm{P}_{4}$ represents the total cost of depreciation on equipment on ith site (N) and

$\alpha_{s}$ are vector of unknown parameters to be estimated

The sources of technical inefficiency effects in equations (1) is modeled in terms of the firm's and processor's characteristics and specified as:

$U_{i}=\delta_{o} \sum_{i=0}^{10} \delta_{n} Z_{i}$ 
where,

$U_{i}=$ technical and allocative inefficiency effects of the equations (2) and (3) respectively;

$\mathrm{Z}_{1}=$ Age of the processor in years;

$\mathrm{Z}_{2}=$ Gender of the processor $(1=$ male, $0=$ otherwise $)$

$Z_{3}=$ Educational level (years);

$\mathrm{Z}_{4}=$ Years of processing experience (years)

$\mathrm{Z}_{5}=$ Duration of processing $(\mathrm{hr})$;

$\mathrm{Z}_{6}=$ Membership of association (1=yes, $0=$ no)

$\mathrm{Z}_{7}=$ Access to credit used in processing (N)

$\mathrm{Z}_{8}=$ Totalsize of processing capacity (ha)

$\mathrm{Z}_{9}=$ dummy for processing technology status of the processor (1=improved; otherwise is 0$)$

$\mathrm{Z}_{10}=$ Training $(1=$ yes, $0=$ no $)$

Economic Efficiency (EE)

This is the multiplication of technical and allocative efficiency,

$\mathrm{EE}=\mathrm{TE} \times \mathrm{AE}$

\section{RESULTS AND DISCUSSION}

\section{Socio-economic characteristics of the respondents}

Socio-economic characteristics of the bio-fortified cassava processors were presented in Table 1. From Table 1, the mean age of the processors was $48( \pm 11.36)$ which shows that the processors were in their productive and active age. They are thus expected to have adequate energy to carry out their processing activities on the processing sites. About $61 \%$ of the bio-fortified cassava processors were female and thus implies that processing of bio-fortified cassava were women dominated in the study area. This agreed with Ehinmowo and Ojo (2014);Adeniyiet al., (2015) that cassava processing is mostly carried out by women in Nigeria. About $77 \%$ of the respondents were married indicating that they were responsible in the study area. The mean years of formal education were $12.72( \pm 4.87)$. This shows that bio-fortified cassava processors in the study area were literate as they possess the basics of educational qualities. This might have influence their decision to ventured into processing of improved cassava varieties (bio-fortified cassava) instead for local cassava as they were better informed. This result agreed with Adeniyiet al., (2015) and Abass et al., 2019 that cassava processors in Nigeria are literate and thus able to read and write. The average household size was $8.25( \pm 4.32)$ which indicates that they had a relatively large household size. Thus, the use of family labour is possible in the processing of bio-fortified cassava in the study area. About $72 \%$ of the respondents do not have access to credit in the study area which might be responsible for the small scale farming they practice. It might also be due to lack of collateral needed to obtain loan. The average years of processing experience was $16.84( \pm 8.76)$ years which indicates that majority of the respondents have been into cassava processing for many years and are thus expected to have the necessary experience to boost their production in the study area. Majority (79\%) of the respondents were into one form of cooperative society or the other. This agree with Ehinmowo and Ojo (2014);Adeniyiet al., (2015). 
International Journal of Agriculture, Environment and Bioresearch

Vol. 5, No. 03; 2020

ISSN: $2456-8643$

1

Table 1:Socio-economic Characteristics of Bio-fortified Vit-A Cassava Processors

\begin{tabular}{|ll|}
\hline Variables & $\begin{array}{l}\text { Bio-fortified vitamin-A } \\
\text { cassava Processors }\end{array}$ \\
\hline Age (years) & $48( \pm 11.36)$ \\
Female (\%) & 61 \\
Married (\%) & 77 \\
Formal education (years) & $12.72( \pm 4.87)$ \\
Household size (\#) & $8.25( \pm 4.32)$ \\
Access to credit(\%) & 72 \\
Years of experience (years) & $16.84( \pm 8.76)$ \\
Membership of association & 79 \\
$(\%)$ & \\
\hline
\end{tabular}

Source: Data Analysis, 2019

\section{Efficiency of Bio-fortified vit-A Cassava processing}

\section{Technical efficiency of Bio-fortified vit-A Cassava processing}

The model specified was estimated by the maximum likelihood (ML) method using frontier 4.1 software developed by Coelli (1995). The ML estimates and inefficiency determinants of the specified frontier were presented in Table 2 . The study revealed that the generalized likelihood function was -16.23 . The likelihood function in Table 2 implies that inefficiency exist in the data set. The likelihood ratio value represents the value that maximizes the joint densities in the estimated model. Thus, the functional form used in this estimation is an adequate representation of the data. The value of gamma $(\gamma)$ is estimated and it was highly significant at $(p<0.01)$ level of probability. This is consistent with the theory that $\gamma$-value should be greater than zero. This implies that $95 \%$ of random variation in the output of the processors was due to the processors' inefficiency in their respective processing sites and not as a result of random variability. Since these factors are under the control of the processors, reducing the influence of the effect of $\gamma$ will greatly enhance the technical efficiency of the processors and increase their output. The value of sigma square $\left(\sigma^{2}\right)$ was significantly different from zero at $1 \%$ level of probability. This indicates a good fit and correctness of the specified distributional assumptions of the composite error terms while the $\gamma$ indicates the systematic influences that are unexplained by the production function and the dominant sources of random error. This means that the inefficiency effects make significant contribution to the technical inefficiencies of bio-fortified processors. However, the estimated coefficients of all the parameters of processing variables (tubers of cassava root, 
labour, charcoal/wood/diesel and depreciation on equipment) were positive and significant at 5 and $1 \%$ level of probability and hence play a major role in bio-fortified cassava processing in the study area.

The average technical efficiency for the processors was 0.72 implying that, on average, the respondents are able to obtain $72 \%$ of potential output from a given mixture of processing inputs. Thus, in a short run, there is minimal scope (28\%) of increasing the efficiency, by adopting the best processing technology and techniques in the study area.

The estimated coefficient for quantity of bio-fortified cassava root was 0.061 which is positive and statistically significant at $5 \%$ level of probability. The estimated 0.061 elasticity of biofortified cassava root implies that increasing quantities of bio-fortified cassava root by $5 \%$ will increase processed cassava output by $6.1 \%$ which means, all things being equal the output is elastic to changes in the quantity of bio-fortified cassava root used. The significance of the biofortified cassava root used is however, due to the fact that bio-fortified cassava root determines to some extent the quantity of the processed cassava obtained.

The processing elasticity of output with respect to quantity of labor was 0.019 which is negative and statistically significant at $1 \%$ level of probability. This implies that a $1 \%$ decrease in labor used will increase bio-fortified cassava output by $1.9 \%$. This implies that labor might have been over used in the study area.

The estimated coefficient (0.030) of quantity of wood/charcoal/diesel was negative and statistically significant at $5 \%$ level of probability. This implies that a unit decrease in quantity of wood/charcoal/diesel will leads to a unit increase in output. The significance of wood/charcoal/diesel used is due to the fact that technical efficiency reduces as additional cost is incurred in the study area.

TABLE 2 .Maximum Likelihood Estimates Results of Stochastic Frontier Model (Technical Efficiency) of Bio-fortified cassava Processing

\begin{tabular}{|lcccc|}
\hline Variables & Parameters & Coefficients & Standard error & t-value \\
\hline Constant & $\beta_{0}$ & $6.659^{* * *}$ & 0.439 & 15.17 \\
Quantity of cassava root $\beta_{1}$ & & $0.061^{* *} 0.0302 .03$ & & \\
Labour & $\beta_{2}$ & $-0.019 * * *$ & 0.005 & -3.80 \\
Charcoal/wood/diesel & $\beta_{3}$ & $0.057^{* *} 0.0242 .38$ & \\
Depreciation on equipment $\beta_{4}$ & 0.243 & 0.3900 .70 & \\
Inefficiency model & & & & \\
Constant $\mathrm{Z}_{0}$ & -111.880 & 74.242 & -1.51 & \\
Age & $1.220 * *$ & 0.566 & 2.16 & \\
\hline
\end{tabular}




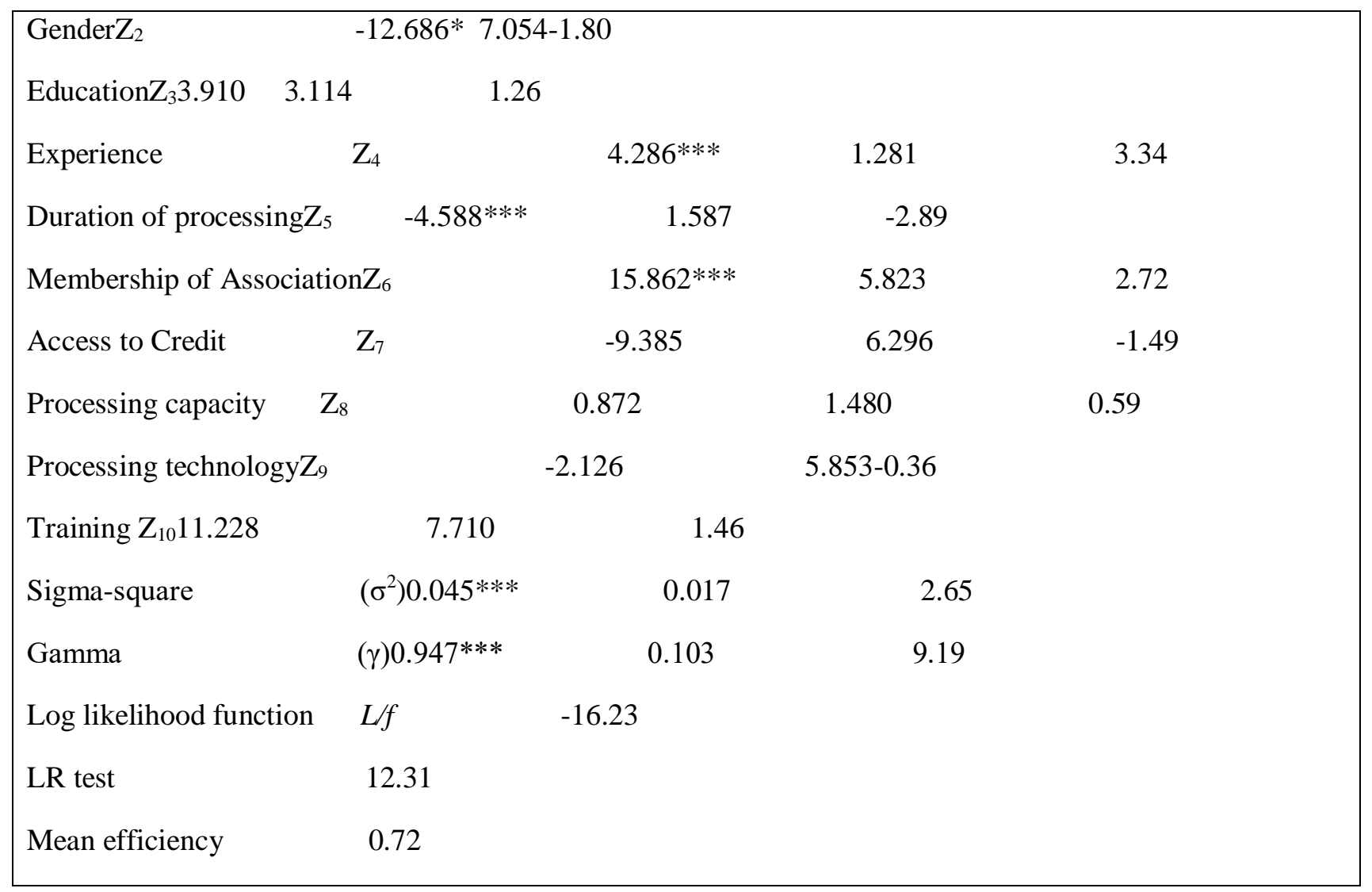

$* * *, * *, *$ significant at $1 \%, 5 \%$ and $10 \%$ level

\section{Source: Data analysis, 2019}

The estimated result of the inefficiency model is presented in Table 2. Generally, a negative sign on a parameter means that the variable increases technical inefficiency, while a positive sign will decrease technical inefficiency. The result shows that all the technical inefficiency variable except age, sex, experience, duration of processing and membership of association were not statistically different from zero.

Age in bio-fortified cassava processing was positive and significant at $5 \%$ for the processors. This shows that increase in age in bio-fortified cassava processing would reducetechnical inefficiency. Processors' age could be associated with skill accumulation over years which could enhance productivity and resource allocations thereby reducing technical inefficiency.

Gender was negative and significant at $10 \%$ for bio-fortified cassavaprocessors. This shows that the gender of the processors could increase technical inefficiency. Female processors might be more technical efficient than their male counterparts because they are more involved in training and skill acquisition which may help them in reducing their technical inefficiency.

Experience in bio-fortified cassava processing was positive and significant at $1 \%$ for the processors. This shows that increase in the years of experience in bio-fortified cassava processing would decrease technical inefficiency. As the processors accumulated more 
experience in the enterprise, they tend to be more productive and efficiently allocate their resources thereby increasing their technical efficiency.

Duration of processing was negative and significant at $1 \%$ for the processors. The negative coefficients for duration of processing imply that duration of processing increases technical inefficiency in bio-fortified cassava processing. The lesser the number of hours use during processing, the more efficient the enterprise will become because lesser resources will be utilized, hence increasing the technical efficiency.

Membership of association was positive and significant at $1 \%$ level of probability for the processors. The positive coefficients for membership imply that membership of association reduces technical inefficiency in bio-fortified cassavaprocessing. Membership of association could afford the processors the opportunity of sharing information on modern processing practices by interacting with other processors. Abass et al. (2019) noted that the increase in efficiency effects through processors belonging to association is as a result of association being a source of quality inputs, information and organized marketing of products. This implied that biofortified cassava processors can market their produce through association in other to have access to higher income.

\section{Estimated Stochastic Frontier Processing Cost Function}

The Maximum Likelihood (ML) estimates of the stochastic frontier processing cost parameters for bio-fortified cassavaprocessing were presented in Table 3. For the processing cost function, the sigma $\left(\sigma^{2}=1.22\right)$ and the gamma $(\gamma=0.99)$ are quite high and highly significant at $1 \%$ level of probability. The high and significant value of the sigma square $\left(\sigma^{2}\right)$ indicate the goodness of fit and correctness of the specified assumption of the composite error terms distribution (Abass et al., 2019). The gamma $(\gamma=0.99)$ shows that $99 \%$ of the variability in the output of bio-fortified cassava processors that are unexplained by the function is due to allocativeinefficiency.

In Table 3. All the estimated coefficients of the parameters of the cost function were positive and statistically significant at $1 \%$ level of probability except depreciation on equipment.

This implies that majority of the input variables were important in bio-fortified cassava processing. The implication of these finding is that if there is an increase in any of the variable input the total cost of processing will increase. This shows that the cost of processing is influenced by the cost of variable input incurred in the production cycle. The most of the selected variables, especially cost of bio-fortified cassava roothad significantly positive impact on biofortified cassava processing returns because it is relatively costly.

Distribution of bio-fortified cassava processors according to technical, allocative and economic efficiencies of bio-fortified cassava processing in the study area

\section{i. Distribution of bio-fortified cassava processors according to technical efficiency}

The frequency distribution of the technical efficiency estimates for bio-fortified cassava processors in the study area as obtained from the stochastic frontier model were presented in Table 4. It was observed from the study that $9.1 \%$ of the bio-fortified cassava processors had a technical efficiency (TE) of 0.81 and above while $90.9 \%$ of the bio-fortified cassava processors operated at less than 0.8 technical efficiency levels as indicated in Table 4 . The processors with the best and least practice had technical efficiencies of 0.72 and 0.44 respectively. This implies 
that on the average, output fell by $9.1 \%$ from the maximum possible level attainable due to inefficiency. The study also suggests that for the average processor in the study area to achieve technical efficiency of his most efficient counterpart, he could realize about $28 \%$ cost savings while on the other hand, the least technically efficient processors will have about 58\% cost savings to become the most efficient processors. This finding is similar to that of Abass et al.(2019).

TABLE 3 .Results of Maximum Likelihood Estimates of Frontier Cost function for biofortified cassava processing

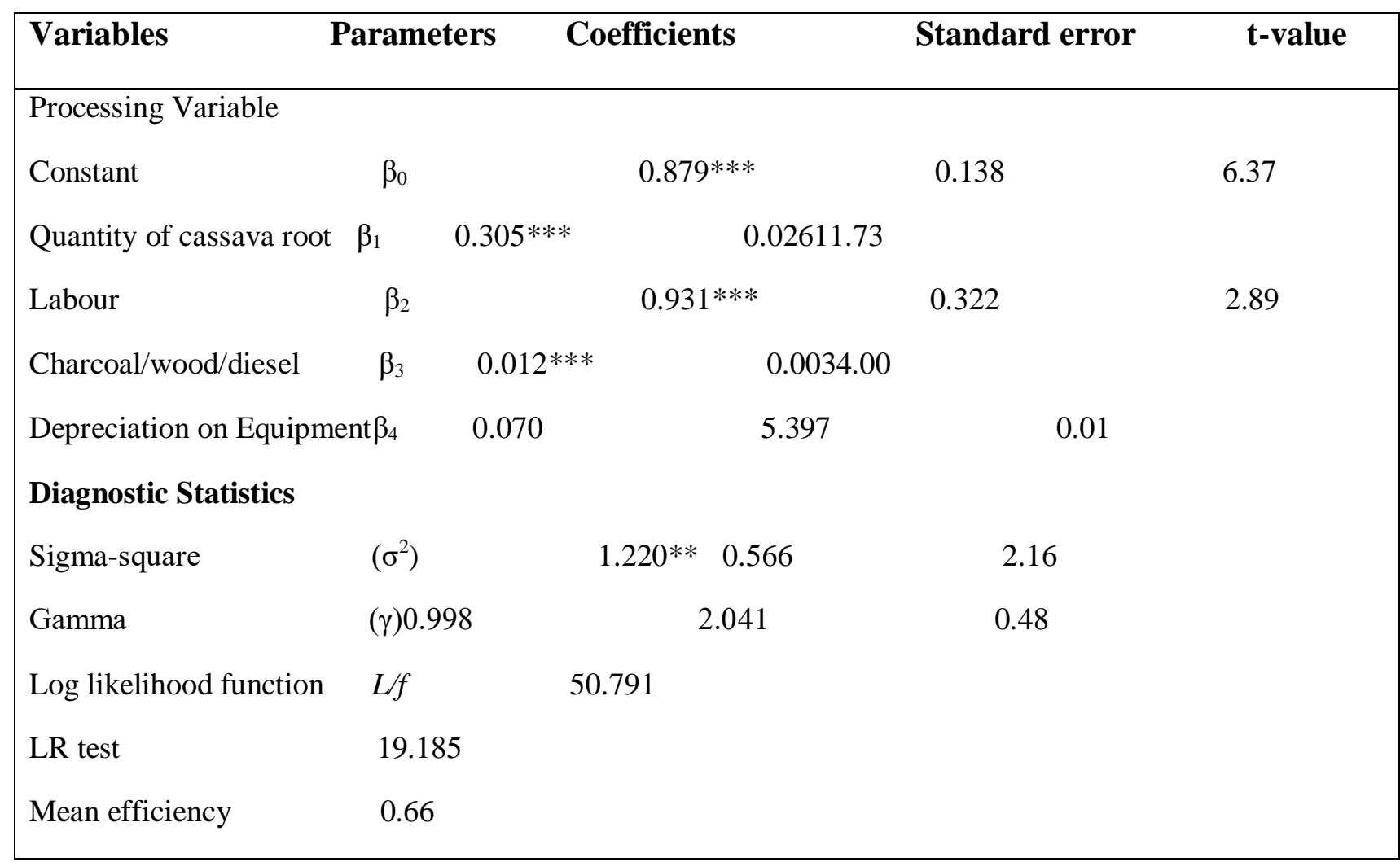

***, **, * significant at $1 \%, 5 \%$ and $10 \%$ respectively

Source: Data analysis, 2019

ii. Distribution of bio-fortified cassava processors according to allocative efficiency

The Maximum Likelihood (ML) estimates of the stochastic frontier cost function for bio-fortified cassava processing were presented in Table 3. The distribution of the allocative efficiency estimates presented in Table 3, indicate that it ranged from 0.20 to 1.00; the mean allocative efficiency was 0.66 . The result indicates that averagebio-fortified cassava processor in the state would enjoy cost saving of about $41 \%$ if he or she attains the level of the most efficient processor among the respondents. The most allocative inefficient processor will have an efficiency gain of $90.5 \%$ in bio-fortified cassava processing if he or she is to attain the efficiency level of most allocative efficient processor in the study area. 
International Journal of Agriculture, Environment and Bioresearch

Vol. 5, No. 03; 2020

ISSN: $2456-8643$

TABLE 4 . Frequency Distribution of Technical, Allocative and Economic Estimates from the Stochastic Frontier Model for Bio-Fortified Cassava Processing

\begin{tabular}{lcccccc|}
\hline & \multicolumn{2}{l}{ Technical efficiency } & \multicolumn{2}{c}{ Allocative Efficiency } & \multicolumn{2}{c}{ Economic Efficiency } \\
\hline Class & Frequency & $\%$ & Frequency & $\%$ & Frequency & $\%$ \\
\hline$<0.2$ & 0 & 0 & 0 & 0 & 9 & 7.5 \\
$0.21-0.40$ & 0 & 0 & 7 & 5.8 & 18 & 15.0 \\
$0.41-0.60$ & 32 & 26.7 & 29 & 24.2 & 69 & 57.5 \\
$0.61-0.80$ & 77 & 64.2 & 75 & 62.5 & 24 & 20.0 \\
$0.81-1.00$ & 11 & 9.1 & 9 & 7.5 & 0 & 0 \\
Total & 160 & 100 & 160 & 100 & 160 & 100 \\
Mean & 0.72 & 0.66 & & 0.65 & & 0.06 \\
Minimum & 0.44 & & 0.10 & & 0.79 \\
Maximum & 0.97 & 0.95 & & \\
\hline
\end{tabular}

Source: Data Analysis, 2019

iii. Distribution of bio-fortified cassava processors according to economic efficiency

The frequency distribution of the economic efficiency estimates for bio-fortified cassava processors in the study area as obtained from the stochastic frontier model were presented in Table 24. It was observed from the study area that no bio-fortified cassava processors had economic efficiency (EE) of 0.81 and above while $100 \%$ of the processors operate at less than 0.8 efficiency level. The mean economic efficiency of the 160 sampled bio-fortified cassavaprocessors in the study area was 0.65 . The bio-fortified cassavaprocessors with the best and least practice had economic efficiencies of 0.79 and 0.06 respectively. This implies that on the average, output fall by $35 \%$ from the maximum possible level due to inefficiency.

The study also suggests that for the average bio-fortified cassavaprocessor in the study area to achieve economic efficiency of his most efficient counterpart, he could realize about $69.6 \%$ cost savings while on the other hand, the least economic efficient processors will have about $119 \%$ cost savings to become the most efficient processor. However, the average economic efficiency of the bio-fortified cassava processors was $65 \%$. This indicates that cbio-fortified cassavaprocessors were economically efficient.

\section{CONCLUSION AND RECOMMENDATION}

The study specifically measured the economic efficiency of bio-fortified cassava processing in the South-Western region of Nigeria. It can be concluded from the study that all the input variables were important in bio-fortified cassava processing. The implication of these finding is 
that if there is an increase in any of the variable input, the total cost of processingbio-fortified cassava will increase. This shows that the cost of processing is influenced by the cost of variable input incurred in the production cycle. It was equally concluded that the average economic efficiency of the bio-fortified cassava processors was 0.65 and that variables such as age, gender, experience, duration of processing and membership of association determines the technical efficiency of the bio-fortified cassava processors in South-Western Nigeria. Efforts should be made by the government to restructure cooperatives societies in Nigeria so that bio-fortified cassava processors would be encourage to join for them to be able to access information that will improve their economic efficiency. Also, agencies, stake holders and government should made credit available for the bio-fortified processors in the study area so that they will be able to adopt appropriate processing technology in other to improve their economic efficiency.

\section{ACKNOWLEDGEMNT}

The authors will like to appreciate the effort of ADPs and Cassava processors association for their help rendered during the time of data collection.

\section{COMPETING INTERESTS}

Authors have declared that no competing interests exist.

\section{REFERENCES}

Abass, A. L.Olarinde, V . Okoruwa, P . Amaza, W . Awoyale, T. Alabi and M. Ndavi (2019).Drivers of Technical Efficiency in Cassava Processing in Nigeria: Implications for a Commercializing Food Sector.Tropicultura, 37(2), 573-588.

Adeniyi, O.R. and Olufunmilola T. Akande (2015).Resource Use and Technical Efficiency in Value Addition to Cassava: A Case Study on Gari and Fufu Processing in Ogun State, Nigeria.American Journal of Experimental Agriculture, 5(2), 139-147.

Cardoso, A. P., Mirione, E., Ernesto, M., Massaza, F., Cliff, J., Haque, M. R., Bradbury, J. H. (2005). Processing of cassava roots to remove cyanogens. J. Food Comp. Anal., 18(5), 451-460.

Chukwuji,C.O.,Inoni, O.E.\&IkeP.C.,(2007).DeterminantsofTechnicalEfficiencyinGariProcessing in Delta State, Nigeria. J. Central Eur. Agric., 8, 3, 327-336.

Egesi, C., Mbanaso, E., Ogbe, F., Okogbenin, E., Fregene, M. (2006). Development of cassava varieties with high value root quality through induced mutations and marker-aided breeding. NRCRI, Umudike Annual Report (pp. 2-6).

Ehinmowo, O. O. and S. O. Ojo. (2014). Analysis of Technical Efficiency of Cassava Processing Methods among Small-scale Processors in South-west, Nigeria. Am. J. Rural Dev., 2(2), 20-23.

FAO, 2003, Food and Agriculture Organization (FAO) website. www.fao.org.

Hillocks R., (2002). "Cassava in Africa”. CABI Publishing. 
Vol. 5, No. 03; 2020

ISSN: $2456-8643$

IITA (2007). A strategy for industrialization of cassava in Africa: Proceedings of a small Group meeting, 14-18 November 2005, Ibadan, Nigeria.

Ilona, P., Bouis, H. E., Palenberg, M., Moursi, M., Oparinde, A. (2017). Vitamin A Cassava in Nigeria: Crop Development and Delivery. Afr. J. Food Agric. Nutr. Dev., 17(2), 1200012025.

Lawal J.O. and Jaiyeola C.O., (2007). Economic Analysis of Cocoa Wine Produced from Cocoa Powder. J. Agric. Food Environ., 5, 2, 71-76.

Parkes, E. Y., Fregene, M., Dixon, A., Boakye-Peprah, B., Labuschagne, M. T. (2013). Combining ability of cassava genotypes for cassava mosaic disease and cassava bacterial blight, yield and its related components in two ecological zones in Ghana. Euphytica, 194(1), 13-24.

Phillips T. P., Taylor D. S., Sanni L. \& Akoroda, M.O., (2004). A cassava industrial revolution in Nigeria: The Potential for a new industrial crop". International Institute of Tropical Agriculture, Ibadan, Nigeria". International Fund for Agricultural Development, Food and Agriculture Organization of the United Nations, Rome, Italy.

Saltzman, A., Birol, E., Bouis, H. E., Boy, E., De Moura, F. F., Islam, Y. Pfeiffer, W. H. (2014). Biofortification: Progress towards a more nourishing future. Bread and Brain, Education and Poverty. Pontifical Academy of Sciences, Vatican City. Scripta varia 125. Retrieved from: www.pas. va/content/dam/accademia/pdf/sv125/sv125-bouis.pdf

Sanni, L. O., Adebowale, A. A., Awoyale, W., Fetuga, G. O. (2008). Quality of gari (roasted cassava mash) in Lagos State, Nigeria. Nig. Food J., 26(2), 125-134.

Talsma, E. F., Brouwer, I. D., Verhoef, H., Mbera, G. N., Mwangi, A. M., Demir, A. Y., MelseBoonstra, A. (2016). Biofortified yellow cassava and vitamin A status of Kenyan children: a randomized controlled trial. Am. J. Clin. Nutr., 103(1), 258-267.

Truman, P. P., Daphnes, S. T., Lateef, S., Malachy, O. A. (2004). The Global Cassava Development Strategy, A Cassava Industrial Revolution in Nigeria. The Potential for a New Industrial Crop". International Fund for Agricultural Development Food and Agriculture Organization of the United Nations P. 9, 16. 